\title{
Avrupa Birliğinde Hegemonya Sorunu ve Almanya
}

DOI: $10.26466 /$ opus.525395

*

\section{Mehmet Soytürk $^{*}$}

* Dr. Öğr. Üyesi, Karadeniz Teknik Üniversitesi, İktisadi ve İdari Bilimler Fak. Trabzon/Türkiye E-Posta: mehmetsoyturk@ktu.edu.tr

ORCID: $\underline{0000-0002-9011-3660}$

\section{Öz}

Avrupa Birliği'nin kuruluş amaçlarından biri Avrupa kıtasındaki savaşlara son vermekle beraber çıkabilecek olası savaşları önlemektir. Avrupa'da günümüze kadar çıkmış olan savaşların birçoğunun sebebi Kıta Avrupa'sındaki devletlerin aralarındaki hegemonya mücadeleleriydi. Kıtada söz sahibi olmak isteyen ve hatta kıtanın birçok ülkesini hükmü altına almak isteyen ülkelerden biri olan Almanya iki dünya savaşının çımasına sebep olmuştur. İki dünya savaşında da Almanya'nın saldırısına uğrayan ve mağdur edilen Fransa özellikle İkinci Dünya Savaşından sonra Almanya'nın kontrol altında tutulması gerektiğini ifade ederek çeşitli girişimlerde bulunmuş̧tur. Nihayetinde Avrupa'da birliğge giden yolun başlangıcı olarak kabul edilen Avrupa Kömür Çelik Teşkilatı'na tanınan yetkilerle Almanya'nın en azından belli sektörleri dolaylı da olsa kontrol altına alınabilecekti. Almanya ile bunca kanlı tecrübeler yaşamış olan ülkelerin buna rağmen son yıllarda farklı beklentiler içerisine girdiğine şahit olmaktayız. Birliğe üye bazı ülkelerin yönetici ve siyasetçileri Almanya'nın Birlik içerisinde daha fazla sorumluluk alması gerektiğini açıkça ifade etmektedirler. Harici bu beklentilerle beraber Almanya dahilinde de benzer sesler yükselmektedir. Almanya'nın Birlik içerisindeki rolünün analizi ile beraber Charles Kindleberger'in hegomonik istikrar teorisi eşiğinde bu beklentiler analiz edilmeye çalışılmıştır.

Anahtar Kelimeler: Avrupa Birliği, Almanya, Hegemonik İstikrar Teorisi, Charles Kindleberger 


\title{
Germany and The Hegemony Question in The European Union
}

\begin{abstract}
One of the reasons for founding the European Union is the ending of wars and the prevention of new wars in the European continent. The reasons for most wars on the European continent were the hegemony struggle between European sovereign powers. One of those who was responsible for the wars is Germany. Because France was attacked by Germany in both world wars, for this reason it was a special concern for France to bring Germany under international control. The European Steel Union was also founded with the intention of keeping Germany under control in this sector at least so that it would not be a danger to the continent again. Despite the bloody experiences with Germany some countries are convinced that Germany takes more responsibility. But similar voices are heard meanwhile also within Germany. Our intention is to analyze Germany's role and to analyze the expectations of Germany in the context of the stability theory of Charles Kindleberger.
\end{abstract}

Keywords: European Union, Germany, Hegemonic Stability Theory, Charles Kindleberger

OPUS (c) Uluslararası Toplum Araştırmaları Dergisi-International Journal of Society Researches ISSN:2528-9527 E-ISSN : 2528-9535

http://opusjournal.net 


\section{Giriş}

Dünya siyasi tarihi incelediğinde Avrupa Birliği'nin şekillenmesi benzeri olmayan bir süreç olduğu anlaşılabilmektedir. Yirminci yüzyılın hemen başında gerçekleşen Birinci Dünya Savaşı'nın henüz şoku atlatılmamışken ikinci bir Dünya Savaşı'nın daha şiddetli ve acımasız bir şekilde yaşanmış olmasından hemen sonra Avrupa'da Birliğe giden yolda ilk anlaşmalar gerçekleştirilmiştir.

Avrupa Kömür Çelik Teşkilatı (AKÇT) olarak başlayan ve bugünkü adı olan Avrupa Birliği ile son halini almış olan Avrupa'daki devletler birliği dünya siyasi tarihinde ayrı bir yer tutmaktadır. Avrupa Kömür Çelik Teşkilatını kuran altı ülke, Fransa, Almanya, Hollanda İtalya, Lüksemburg ve Belçika, bu anlaşmayla beraber kendi egemenliklerinden bir bölümünü gönüllü olarak kendi aralarında oluşturmuş oldukları bir üst kuruma devretmişlerdir. Bu daha önce şahit olunmamış bir siyasi gelişmedir.

Yirminci yüzyılın başında yaşanmış olan iki acımasız savaş tecrübesi kesinlikle Avrupa' da bir devletler birliğine doğru giden yoldaki en önemli sebepti. Daha önceki yüzyıllarda da Kıta Avrupa'sında yaşanmış olan savaşların tahribatlarının üzerine gelen bu iki acı tecrübe Avrupalıların artık kalıcı bir çözüm için doğru adımların atılması gerekliliği bilincine ulaştırmıştı. O yılların en önemli amacı olan Avrupa'da savaşların önlenmesi ve kalıcı barışın sağlanması için gerekli doğru adımların atılması hemen II. Dünya Savaşından sonra gerçekleştirilmiştir.

Kıta Avrupa'sında gerçekleşen savaşların en önemli sebeplerinin başında kıtadaki hegemonya mücadeleleriydi. Yüzyıllar süren bu mücadelelerin mutlak bir galibinin olduğunu ifade etmemiz mümkün değildir, bazen biri bazen de diğer devlet kıtada gücü eline geçirmiş ve hegemonyasını oluşturmayı başarmıştır. Kıta Avrupa'sındaki hegemonya mücadelelerinden biri uzun yıllar Fransa ve Avusturya-Macaristan arasında gerçekleşmiştir. Fransa ve Avusturya-Macaristan arasındaki hegemonya mücadelesi sadece iki devlet arasında değildi aynı zamanda da iki ülkeyi yöneten hanedanlar arasındaki mücadeleydi. Hiçbir devlet diğer devlet veya devletlere daimî olarak hegemonyasını kabul ettirip mevcudiyetini bu şekilde devam ettirme başarısını gösterememiştir. Böyle olmasının sebeple- 
rine çok detaylı bir şekilde girmeden İngiltere'nin rolüne kısaca değineceğiz. İngiltere kendi geostratejik konumu itibariyle Kita Avrupa'sinda denge politikasını bozabilecek herhangi bir devletin hegemonyasını kabul etmeyerek sürekli Kıta Avrupa'sındaki güçler arasında dengelerin sağlanmasını amaçlamıştır. Zaman zaman ise yeniden dengelerin oluşması için mücadele etmiştir. Böylece İngilizler Avrupa'da olan güç mücadelelerine aktör olarak katılmamış ama dengeleri değiştirebilecek müdahalelerde bulunabilmiştir (Gollwitzer, 1972, s.245-283).

Yirminci Yüzyıla gelindiğinde ise Avrupa kıtasında Orta Çağ'dan itibaren süre gelen hegemonya mücadelelerine son verilmesi gerekiyordu. Bunu yaparken savaşların bitirilmesi ve aynı zamanda da sosyo-ekonomik kazanımların devamının sağlanması gerekmekteydi. İkinci Dünya Savaşından sonra yapılan antlaşmalara baktığımızda iki önemli amaç göze çarpmakta; savaşsız bir kıta ve refahın sağlanması.

Yukarda bahsettiğimiz gibi 20. yüzyılda Avrupa kıtası iki tane büyük, kanlı ve vahşi savaşa sahne olmuştur. Bu savaşların ikisinde de özellikle Fransa mağdur olmuş ve bundan dolayı da saldırgan olan Almanya'nın kontrol altına alınması gerektiği fikrini ortaya atmış ve bu fikir etrafında taraftar toplamaya uğraşmıştır. Fransa, İkinci Dünya Savaşından sonra da Almanya'nın artık kontrol edilmesi gerektiğini fikrini savunmuş ve bu doğrultuda girişimlerde bulunmuştur. Bu girişimlerin en önemli sonucu ise 1951 yılında kurulan Avrupa Kömür Çelik Teşkilatı'dır. Kurulan bu teşkilat ile beraber en azından kömür çelik sektörlerinde dolaylı da olsa Fransa Almanya'yı kontrol etme imkânına sahip olmuştur (Woyke, 1984, s.22).

AKÇT'nin kurulmasıyla beraber Avrupa kıtasında hegemonya mücadelesi verilirken, beraber kurulmuş olan bir kurum içerisinde aynı mücadele devam edecek miydi? Yukarıda da açıklamaya çalıştığımız gibi Kıta Avrupa'sında yüzyıllardır kıtada söz sahibi olmak isteyen ülkeler arasında hegemonya mücadeleleri yapılmıştır. Bu mücadeleler kimi zaman Fransa ve İspanya arasında, kimi zaman Fransa ile Avusturya-Macaristan İmparatorluğu arasında, kimi zamanda Fransa ile Almanya arasında gerçekleşmiştir. Özellikle 19. yüzyıldan itibaren Almanya'nın kendi iç mücadelelerinden sıyrılıp bütünleşebilmesinden sonra Fransa ile olan hegemonya mücadelesi 20. yüzyılda kendisini en acımasız ve en kanlı şekilde 
göstermiştir. Fransa'nın iki dünya savaşında da Almanya tarafından saldırıya maruz kalması, akıllara bu iki devletin Avrupa Birliği içerisinde de hegemonya mücadelesine girişecekler mi sorusunu getirmektedir. Makaleyi yazmaktaki amacımız Avrupa Kömür Çelik Teşkilatının kurulmasından günümüze kadar olan süreçte Almanya'nın kendisini Birliğin içerisinde nasıl tanımladığ 1 ve hegemonya mücadelesi verip vermediğini analizini gerçekleştirmektir.

\section{Hegemon ve Emperyal Kavramları}

Bildiğimiz gibi hegemonya uluslararası ilişkilerde devletler arasındaki anarşinin karşıtı olarak kabul edilirken devletler arası hiyerarşinin nasıl olacağ ile ilgili bir açıklama teorilerde bulunmamaktadır (Sönmezoğlu, 2012, s.137, 139, 205). Alman siyaset bilim ve tarihçisi Ulrich Menzel Dünyanın Düzeni- Devletler Dünyası Hiyerarşisinde Imparatorluk ve Hegemonya (Die Ordnung der Welt. Imperium und Hegemonie in der Hierarchie der Staatenwelt) adlı eserinde imparatorlukların yükselme ve çöküş dönemlerinin kıyasında, emperyalliği uluslararası ilişkilerde hiyerarşik yapının hegemonya ya göre daha yumuşak ve değişken bir şekli olarak tanımlamaktadır (Menzel, 2015, s.29). Herfried Münkler ise Imparatorluklar (Imperien) adlı eserinde emperyalliği merkezi tabanl sinırsız hakimiyete dayah düzen olarak tanımlamıştır (Münkler, 2007, s.16). Hegemonya ise herkesin eşit olduğu fakat aralarından birinin primus inter pares, eşitler arasında birinci olduğu, bir düzendir (Zielenka, 2006, s.12). Adı geçen iki tanımdan yola çıkarak Avrupa Birliği'nin etrafındaki komşu devletlere karşı bir emperyalliğin mümkün olabileceğinden bahsedilebilinir. Avrupa Birliği içerisinde ise sadece hegemonik bir ilişkinin mümkün olabileceği varsayımından yola çıkarak Almanya'nın Avrupa Birliği içerisindeki rolünü analiz etmeye çalışılacaktır.

\section{Alman Dış Politikasının Temel Esasları}

İki Dünya Savaşı'nın hem müsebbibi hem de mağlubu olan Almanya, Avrupa kıtasının hâkimiyetini eline geçirme sevdası ile Avrupa ve dünyada sayısız insanın ölümüne sebep olmuştur. Aynı Almanya mağlup olduğu İkinci Dünya Savaşı'ndan sonra sayısız sorunlarla karşı karşıya kalmıştır. 
Bu sorunların en önemlilerinden biri savaşın galibi batılı devletlerinin ülkenin batısını, savaşın diğer bir galibi olan Sovyetler Birliği'nin ise ülkenin doğusunu kontrol altında tutmasıydı. Batılı kapitalist ülkelerin askeri kanadı olan NATO ve komünizmin askeri kanadı Varşova Paktı Almanya topraklarında direk karşı karşıyaydılar ve böylece de Almanya da kontrol altına alınmıştı. Daha sonraki yıllarda ne kadar batılı devletler ülkenin kontrolünü Federal Almanya Cumhuriyetine devretmiş olsalar da ülkenin doğusunda yeni bir devlet kuruldu ve artık iki tane Almanya olmuştu. Toprakların doğusunda olan Demokratik Alman Cumhuriyeti Rusya'nın kontrolünde komünist idare şekliyle varlığını Varşova Paktı'nın kendisini lağv etmesine kadar devam ettirmiştir. Federal Alman Cumhuriyeti'nin ise kendisini tekrar toparlayarak Avrupa için tekrar tehlike olmaması adına bir şekilde kontrol altında alınması gerekiyordu. Özellikle Fransa bu konuyla ilgili girişimlerde bulunmuştur. Avrupa Kömür Çelik Teşkilatı'nın kuruluş amaçlarında biri de Almanya'yı bu şekilde kontrol altında tutmaktı. Bu amaçla Almanya en başında beri bu teşkilata dahil edilerek önce Avrupa Kömür Çelik Teşkilatı akabinde Avrupa Ekonomik Topluluğu, Avrupa Topluluğu ve nihayetinde Avrupa Birliği ile kontrol altına alınmış oldu. İkinci Dünya Savaşı'ndan sonra kurulan iki kutuplu dünya düzeni 1989-1991 yılları arasında Batı-Doğu çekişmelerinin sona ermesiyle birlikte son bulmuştur. Bu yıllarda Avrupa'nın ortasında daha önce Doğu ve Batı diye ikiye bölünmüş olan Almanya'nın tek devlette birleşmesi gerçekleşmiştir.

İkinci Dünya Savaşı'ndan sonra Sovyetler Birliği'nin kontrolü altında kalmış olan ve komünist sistemle idare edilen Alman Demokratik Cumhuriyeti (DDR, Deutsche Demokratische Republik) artık Sovyetler Birliği'nin boyunduruğundan kurtulmuş ve iki Almanya tek bir idare altında bir araya gelmiştir. İki Almanya'nın birleşmesi, Federal Alman Cumhuriyetinin Avrupa kıtasının ortasında yeni dünya düzenin galiplerinden biri olmasını sağlamıştır. Avrupa'da İkinci Dünya Savaşından sonra oluşturulmuş olan düzen revize edilmiş, savaşın galipleri olan Rusya, İngiltere ve Fransa karşısında iki Almanya'nın Federal Almanya'nın idaresinde birleşmesi Almanya'nın öz güven kazanmasına sebep olmuştur. İki Almanya'nın birleşmesinden sonraki süreçte yeni Federal Almanya hızlıca ekonomik bir güç olmuş ve böylece kendisini diğer devletlere de kabul ettirme başarısını göstermiştir. 
Federal Almanya Cumhuriyeti'nin dış politikasının temel esasları, daha önce Batı Almanya döneminde de olduğu gibi tek başına hareket etmeyip, Avrupa Birliği, NATO ve Birleşmiş milletler gibi uluslararası kurum ve kuruluşlar ile beraber hareket etmek olarak özetlenebilir (Bredow, 2006, s.246).

Federal Almanya Cumhuriyetinin dış politika anlayışı 11 Eylül 2001 tarihinde ikiz kulelere yapılan terör saldırısına kadar bu prensip etrafında şekillenmiştir. Dünya Ticaret Merkezi'ne yapılan terör saldırılarından sonraki süreçte Federal Almanya Cumhuriyeti Başbakanı Gerhard Schröder, İngiltere ve Fransa gibi Amerika Birleşik Devletleri ile sınırsız dayanışma içerisinde olduklarını açılamıştır (Kleine, 2004, s.46). Alman iktidarının Amerika Birleşik Devletleri'ne dayanışma açıklaması yapmış olmasına rağmen ABD'nin öncülügüünde 2003 yılında başlatılan Irak Savaşı'na dahil olmamıştır. Almaya savaş yanlısı cephede değil de Fransa gibi savaşa biraz daha eleştirisel bir yaklaşım sergilemiş ve oluşturulan koalisyonun savaş çağrılarına olumsuz yaklaşmıştır. Daha sonra Birleşmiş Milletler Güvenlik Konseyi'nde Batı devletlerinin Libya'ya karşı askeri müdahalede bulunabilmelerinin önünü açan 1973 nolu Kararın oylanmasında Almanya'nın çekimser kalarak tarihinde ilk kez ABD, İngiltere ve Fransa gibi Batı devletlerinin değil de Rusya, Çin, Hindistan ve Brezilya gibi devletlerin yanında yer almıştır (Baumann, 2007, s.69). Federal Alman Cumhuriyeti hükümetinin, Irak ve Libya konularında almış olduğu tavırla, müttefiklerine kendi menfaatlerine aykırı olabilecek gelişmelerde yanlarında olmayacağı mesajını vermek istemiştir. Alman hükümetinin Irak ve Libya kararlarında takınmış olduğu tavır, müttefiklik bünyesinde kendisi için tanımlanan rolünün reddi, günümüze kadar devam etmekte olduğunu ifade edebiliriz. Bu yıllardan beri uygulamaya koymuş olduğu yeni dış politika anlayışını pragmatik bir yaklaşım olarak tanımlayabiliriz. Almanya'nın pragmatik dış politika anlayışını günümüzde de uyguladığı rahatlıkla ifade edilebilir.

\section{Almanya'nın Avrupa Birliği Politikaları ve Birlik İçerisinde Hege- monya Dağılımı}

Yukarıda açıklamaya çalıştığımız Alman dış politikasının ana hatlarından sonra Almanya'nın Avrupa Birliği ile olan ilişkileri ve Birliğin içerisindeki 
yeri ile ilgili analizimize devam edeceğiz. Avrupa'nın birleşmesi Almanya'da Konrad Adenauer, Helmut Schmidt veya Helmut Khol gibi tarihe geçmiş şansölyeler döneminde devlet politikası seviyesindeydi ve Avrupa'daki bu birleşme en önemli hedeflerden biriydi.

Avrupa'da devletler arasında birliğin oluşturulmasında öncelikle Almanya ve Fransa'nın uzlaşması Birlik içerisinde resmi olmayan bir siyasi güç ve karar verme ekseni oluşturulmuş. Söz konusu uzlaşma ile oluşturulan bu eksen Avrupa'da bir devletin hegemonya oluşturmasının önündeki en büyük engeldi. Avrupa kıtasının önceki yıllarına baktığımızda Paris ve Berlin arasındaki hegemonya mücadelesi çoğu kez savaşlara sebep olduğu görülmektedir. Bu rekabet kısmen de olsa Napolyon döneminden beri en büyükleri Birinci ve İkinci Dünya Savaşları olmak üzere savaşlara sebep olmuştur.

İkinci Dünya Savaşından sonra Almanya ve Fransa arasındaki husumetin kaldırılması, ekonomilerin iç içe girmeleri Avrupa projesinin temelini oluşturmuştur. Avrupa Kömür Çelik Teşkilatının kuruluşundan günümüze kadar olan süreçte Avrupa birleşmesinde Berlin - Paris ekseninin kendi aralarında göstermiş olduğu anlayışa bağlı olarak ilerlemiştir. Fransa ve Almanya Birlik içerisindeki lokomotif rolleri özellikle Büyük Britanya'nın referandum yoluyla Birlikten ayrılma kararı almasından sonra daha da belirgin ve önemli bir hal almıştır.

Brexit oylamasından sonra Almanya'nın ve Fransa'nın Birlik içerisindeki rolleri ve önemleri artmakla beraber Almanya için ayrıca belirtilmesi gereken 2008 dünya ekonomik krizidir. Bütün dünyayı etkisi altına alan ekonomik krizde Almanya'nın güçlü ekonomisi Almanya'nın Avrupa Birliği içerisindeki önemini daha da arttırmıştır. Dünya ekonomik krizinden sonra ortaya çıkan "Avro Krizi"nden sonra Almanya'nın Birlik içerisindeki ağırlığı hakkında çok şeyler yazılıp çizilmiştir. Ekonomik krizin bütün dünyayı etkisi altına aldığı bir dönemde Almanya'nın artan ekonomik gücü ve buna paralel olarak diğer ülke ekonomilerinin durağanlık göstermeleri Birlik bünyesinde alınacak kararlarda kendisini daha güçlü duruma getirmiştir. Almanya'nın bu denli ekonomik bir güç haline gelmesi kendisini siyasi olarak ta güçlü bir konuma taşımasına vesile olmuştur. Fakat, Almanya'nın bu duruma gelmesi yeni bir hegemonik gücün gerek- 
liliği tartışmalarının önünü açmasına sebep olmuştur. Hegemonya ve hegemon tartışmalarında mevzu Almanya olunca yapılan tartışmaların önemi de tabii ki artmaktadır.

Avro Krizi döneminde Birlik içerisindeki oylamalarda, Almanya'nın diğer ülkeleri kendi tercihleri doğrultusunda karar vermelerine zorlaması hegemonya tartışmalarını daha da alevlendirmiştir. Bu konuda verilebilecek en doğru örnek Almanya'nın 2009 yılında kendi bütçe açığını frenleyebilmek için uygulamaya koymuş olduğu çeşitli mekanizmaları Birlik dahilinde kabul edilip üye ülkelerinin kendi Anayasalarına dahil etmeleri baskısıdır (Aschauer, 2017, s.215). Daha sonraki yıllarda bu doğrultuda 2011 yılında yapılan bir Avrupa Birliği Zirvesinde Almanya'nın diğer ülkeleri de ikna etmesi "Avrupa'nın hegemonu" tanımlamasına yol açmı̧stır. Bu tanımlamayla beraber Avrupa'da bir hegemona ihtiyaç olup olmadığı yönünde çokça fikirler beyan edilmiştir (Geiger, 2017, s.201).

Avrupa'da lider bir ülkenin olması gerektiği yönünde ve bu ülkenin de Almanya olması gerektiğini açıkça ifade eden bir siyasetçiye dikkat çekmenin faydalı olacağı düşüncesindeyiz. Uzun yıllar Polonya Dışişleri Bakanı görevinde bulunmuş olan ve aynı zamanda da eski bir gazeteci olan Radoslaw Sikorski Berlinde gerçekleştirilen bir Konferansta güçlü bir Almanya'dan değil de pasif bir Almanya'dan korktuğunu ifade etmiştir (DGAP, 2011). Sikorski daha sonra Alman Die Welt gazetesinde kaleme aldığı yazısında konferanstaki ifadesini teyit ederek Almanya'nın Birlik içerisindeki rolünün aktif olması gerektiği yönde açılamalarını yinelemiş ve Almanya'nın Avro Bölgesi'nin tekrar düzlüğe erişebilmesi için diğer ülkelere yardım etmesi gerektiğini ifade etmiştir (Die Zeit 2011, s.49). Sikorski'nin ifadelerinden Avrupa Birliğinde sorunların üstesinden gelinebilmesi için güçlü ve lider bir ülkeye ihtiyaç olduğunu ve bu rolü yerine getirebilecek kapasitenin Almanya'da olduğunu, bundan dolayı da aktif rol alması gerektiğine inandığı anlaşılmaktadır.

Charles Kindlberger hegemonik istikrar teorisinde, dünya ticaretinin sorunsuz işleyebilmesi için bir hegemon güç'ün gerekliliğinden yola çıkarak 1929 ekonomik krizin oluşum sebebinin Amerika Birleşik Devletleri'nin dengeleyici güç olmak istememesinden kaynaklandığını iddia etmektedir. Kindleberger, dünya ekonomisinin istikrarlı bir şekilde ayakta kalabilmesi için güçlü ve lider bir ülkenin gerekliliğinden bahsetmektedir. Büyük Britanya'nın 18. ve 19. yüzyıllarda dünya ekonomisinde üstlenmiş 
olduğu rolü, 20. yüzyılda ABD'nin üstlenip sürdürmesi gerekiyordu fakat, bu rolü üstlenmedikleri için 1929 yılında dünya büyük bir ekonomik bühran yaşamıştır. Amerika Birleşik Devletleri 20. yüzyılın hemen başlarında üstlenmesi gereken bu rolü ancak İkinci Dünya Savaşından sonra, Bretten Woods Kararları ile doların dünya ticaret birimi olması ve böylece dünya ticaretine liberal anlamda yön vermeye başlaması ile dünya ekonomi ve ticaret sistemi işlemeye başlamıştır, şeklinde Kindleberger analizine devam etmiş̧tir (Rode, 2002, s.23). Hegemonik istikrar teorisi doğrultusundan ABD'nin rolünü açıklamaya devam edecek olursak, ABD sahip olduğu gücü ikinci dünya savaşından sonra kesinlikle kötüye kullanmamış, Batı Avrupa'nın ve Japonya ekonomilerinin kalkınıp güçlenmelerine yardımcı olduğu da Kindleberger'in iddiaları arasında yer almaktadır (Rode, 2002, s.24).

Alman Federal Maliye Bakanı Wolfgang Schäuble Kindleberger'e atıfta bulunarak, onun bilgi ve tecrübelerinden "Avro-Krizi"nde faydalanılmalıdır şeklinde açıklama yapmıştır. Schäuble açılamalarının devamında Kindleberger'in mesajının 2010 yılında daha öncesinde olmadığı kadar önemli bir hale geldiğini de ayrıca vurgulamıştır. Schäuble 'ye göre Almanya ve Fransa'nın ABD’nin 1929 krizinden önce kendisini istikrar sağlayıcı hegemon olarak görmediği yıllardaki gibi değil de İkinci Dünya Savaşından sonra üstlenmiş olduğu görev doğrultusunda Avrupa Birliğinde istikrar sağlayıcı hegemon rolünü kabul etmeleri gerektiğini her iki devlete seslenerek ifade etmiştir (Zimmermann ve Dür, 2016, s. 238).

\section{A. Avrupa Birliği'nin bir Hegemona İhtiyacı var mı?}

"Avro Krizi" ve öncesinde patlak veren ekonomik kriz döneminde Avrupa Birliğinde alınan kararlarda Almanya'nın gücü kendisini hissettirmiştir. Avrupa Birliği'nin en güçlü ekonomisine sahip olan Almanya bu dönem de Birlik içerisinde öncü rolü kabul etmiş ve yerine getirmiştir. Sonraki dönemde ise üstlenmiş olduğu liderlik rolünü Libya krizinde pasif kalarak devam ettirmiştir fakat bu pasifliğinden dolayı da oldukça fazla eleştirilmiştir (Milosevic, 2012, s.117-120). Diğer taraftanda Ukrayna krizine aktif bir şekilde dahil olup yön vermeye çalı̧̧ması ise ABD tarafında kabul görmeyip eleştirilmiştir (T-Online, 2015). Suriyeli göçmenler 
krizinde ise yine aktif bir rol üstlenmiştir ve diğer Avrupa ülkelerine nazaran göçmenlere karşı daha anlayışlı yaklaştığı için ve Türkiye ile göçmen sorunu ile ilgili anlaşma yolunu seçtiği için Almanya'daki muhalefetten ve bazı ülke liderlerinin eleştirilerine maruz kalmıştır. (Kiehen, 2016, s.9-12).

Suriyeli göçmen krizi döneminde olduğu gibi üye devletlerin Avrupa Birliği'nin yönetmeliklerine, kurumlarına, devlet ve hükümet başkanları tarafından alınan kararlara uymamaları, Birlik içerisinde güçlü bir hegemonun gerekliliği ile ilgili tartışmaları alevlendirmiştir. Bu dönemde oluşturulamayan ortak hareket, Birlik dahilinde bir hegemona ne kadar ihtiyaç olduğunu gösteren gelişmeler olarak karşımıza çıkmaktadır. Federal Alman Cumhuriyeti iktidarının istikrarsız siyaseti hegemon olabilme ihtimaline zarar vermektedir. Ayrıca, Avrupa Birliği kurumları arasında henüz tam anlamıyla tanımlanmamış yetki dağılımları da olunca Birlik içerisinde ortak eylem ve işbirliği ihtiyacı artmaktadır.

\section{B. Avrupa Birliği'nde ihtiyaç duyulan Hegemon Almanya mı?}

Uluslararası hegemon bir ülke konuma ulaşabilmek için sadece güçlü bir ekonomik yapıya sahip olmak yetmemektedir, aynı zamanda da aktif bir dış politika anlayışı sahip olmak gerekmektedir. Güçlü olabilmek için ise ekonomik ve siyasi öz kaynaklara sahip olunması gerekirken hedeflere ulaşabilmek için ise ayrıca irade sahibi olunması gerekmektedir. Bu özellikler çerçevesinde Federal Alman Cumhuriyeti İkinci Dünya Savaşından sonra göstermiş olduğu ekonomik performans ile dünyada belli itibar sahibi olmuş ve bununla beraber küçümsenmeyecek derecede de soft power gücüne ulaştı̆̆ını ifade edebiliriz (Jerabek, 2011, s.51).

Federal Almanya Cumhuriyeti, Avrupa Birliği'nin ve genel anlamda da Avrupa kıtasının en fazla nüfusa sahip ülkesi konumundadır ve aynı zamanda da ekonomisi en güçlü ve istikrarlı ülkesidir. Bu özellikleri ile beraber en güçlü silahlı kuvvetlere sahip olma potansiyelini de içinde barındırmaktadır. Coğrafi olarak Kıta Avrupa'sının ortasındadır, etrafının tamamen komşu ülkelerle çevrili olmasından dolayı en fazla komşuya sahip ülkedir. Avrupa Birliği'nin üye sayısını arttırdığı yıllarda ve Birlik içerisinde uyumlaştırmanın çok önemli olduğu yıllarda kendi ülke menfaatlerini Birlik menfaatlerinin arkasına sıralandırmayı bilmiştir (Jerabek, 
2011, s.99). Fransa ile olan diyaloğuna son derece önem veren Almanya bütün bu olup bitenler gerçekleşirken Fransayı da yanına çekmeyi ihmal etmemiştir. Avrupa'nın diğer ülkeleri için, kısa zamanda iki tane dünya savaşına sebebiyet vermiş olan bir devletin tekrardan güçlenerek hegemon ülke konumuna ulaşması kabulü zor bir durum olduğunu ayrıyeten belirtmekte fayda vardır.

\section{Almanya Hegemon olduğu Avrupa Birliği'ni nasıl bir Sonuç Bekle- mektedir?}

Avrupa Birliği'nde hegemon bir ülkenin olmasının olumlu sonuçlarının başında Avrupa'nın aynı düşünceleri paylaşması ve olası kararların daha hızlı alınabilmesi ihtimali gelmektedir. Ayrıca dışarıya karşı daha güçlü ve tutarlı olmak adına bir bütünlük içerisinde olunduğu izlenimi verebilecektir. Bunlara ek olarak ABD, Rusya ve Çin gibi ortak veya rakiplere karşı daha net bir tavır koyulması mümkün olabilirdi.

Almanya'nın ulusal siyaseti doğrultusunda sunduğu çözümleri birebir Avrupa Birliğine uyarlamadan kabul ettirmeye çalışmasının Birlik nezdinde tepkiyle karşılanma ihtimali daha önceden de olduğu gibi oldukça yüksektir. Böyle bir yaklaşımdan ziyade Birlik için gerekli olan çözümlere üye devletlerle birlikte ulaşılması daha fazla kabul görme ihtimaline sahiptir. Ancak bu şekilde Almanya kendisini kabul ettirebilme ihtimalini yükseltebilecektir. Aksi halde Birlik dahilinde Almanya'nın hegemonluğu kabul görmeyecektir ve Birlik içerisinde sağlanmaya çalışılan uyum tersi bir istikamet alarak çözülmeye yol açabilecek ve sonucunda ise Birlikten ayrılmalar söz konusu olabilecektir.

\section{Sonuç}

Avrupa Birliği dünyayı olumsuz etkileyen ekonomik krizden hemen sonra "Avro-Krizi" ni yaşaması ve onun hemen akabinde Brexit'le beraber en önemli ve güçlü üyelerinden biri olan Birleşik Krallık'ı kaybetmesiyle gittikçe kaotik bir duruma sürüklenmektedir. Bu önemli ve büyük gelişmelerle beraber göçmen krizinde uyum ve birlik görmemiş olması bizlere Birliğin girmiş olduğu bu kaotik ortamdan kolay kolay çıkamayacağını göstermektedir Avrupa Birliği kurumlarının yetkilerinin sınırlı kaldığ 
durumda Brüksel merkezli bir çözümün oraya çımasını beklemek fazlaca iyimser olacaktır.

Dikkate alınması gereken diğer bir husus ise ABD'nin kendisini Avrupa'dan geri çekmesi ve Uzak Doğu'ya doğru yönelmesidir. İkinci Dünya Savaşından sonra ABD ekonomisinin "gizli eli" Avrupa'da bir düzenleyici olarak üstlendiği rolü başarıyla yerine getirmiştir. Günümüze geldiğimizde ise Amerika Birleşik Devletleri ekonomik çıkarlarını Avrupa'da değil de Çin'de görmesi ve yönünü daha ağırlıklı olarak o tarafa çevirmesi Avrupa'da bir siyasi vakum bırakma ihtimalini doğurmuştur. Uluslararası alandaki bu gelişmeleri göz önünde bulundurduğumuzda Avrupa Birliği'nde bir hegemon güce ihtiyaç duyulacağını ifade edebiliriz. Bu Güç'ün ise şimdiye kadar göstermiş olduğu olumsuz performans ve kendi içindeki belirsizlikten dolayı Brüksel'in olamayacağı da gün gibi ortadadir.

Avrupa Birliği'nin siyasi geleceği Almanya'nın göstereceği performansa bağlı kalmaktadır. Almanya için önemli olan mazideki hatalarından ders çıkartıp onları tekrarlamamaktır. Böylece Kıta Avrupa'sının ve Avrupa Birliğinin güçlü ve belirleyici ülkesi haline gelebilecektir.

Almanya kendisinin ve Birliğin ortak çıkarları doğrultusunda öncülük ettiği sürece Birliğin diğer ülkeleri tarafından kabul görebilecektir. Alman hükümetlerinin bu beklenti doğrultusunda hareket ederken dikkat etmeleri gereken önemli bir husus ise kendi ulusal kamuoyunda Avrupa Birliği karşıtlığının yükselmesini engellemektir. Kamuoyunda Birlik karşıtlığ1nın yükselmesini önleyebilmek için Avrupa projesinin ne kadar önemli ve gerekli olduğunun anlatılmasına önem verilmelidir. Ayrıca ülke ve Birlik menfaatleri arasındaki denge bozulduğu taktirde gelişmeler olumsuz bir seyir almaya başlayacaktır. Bu sebeple menfaatler arası dengenin sağlanmasına itinalı yaklaşılmalıdır.

Özellikle belirtmemiz gereken diğer önemli bir sonuç ise Almanya'nın Avrupa Birliğine üye ülkelere rağmen birliğe yön verebileceği veya hüküm sürebileceği ihtimalinin oldukça düşük olmasıdır. Almanya'nın Avrupa'ya yaşatmış olduğu bunca acı tecrübeye rağmen diğer üye ülkeler tarafından böyle bir rolü kabul görmeyecektir.

Üzerinde düşünülmesi gereken diğer bir husus ise Almanya'nın Birlik içerisinde kendisine biçilen ve kendisinden beklenen bu rolü mevcut iktidarla yerine getirip getiremeyeceğidir. Hristiyan Birlik partilerinin lideri 
sayın Merkel 2017 yılında yapılan Federal Meclis seçimlerinde oylarında düşüş yaşamış olmasına rağmen birinci parti olarak tamamlamıştır. Seçimlerden sonra hükümet kurulabilmek için yeni koalisyon ortakları arayışına giden Hristiyan Birlik Partisi bu arayışında başarılı olamayınca eski koalisyon ortağı olan Sosyal Demokrat Partisi ile yeni hükümeti kurmak zorunda kalmıştır. Kurulan yeni koalisyon hükümetinin bir önceki hükümetten çok farklı olmaması uygulanacak olan uluslararası politikada çok büyük değişikliklerin olmayacağı anlamını da taşımaktadır. 
EXTENDED ABSTRACT

\title{
Germany and The Hegemony Question in The European Union
}

\author{
Mehmet Soytürk
}

Karadeniz Technical University

Charles Kindleberger's hegemonic stability theory (Hegemonic Stability Theory) argues that the state must have a leading role in the economic power of the state, with a high military capability and a role in the international system. Hegemonic stability theory was developed by US academics under the leadership of Charles Kindleberger and consists of synthesis of realist and liberal movements.

In our study, we tried to analyze the hegemonic struggle in the European Union from the perspective of Hegemonic Stability Theory. Charles Kindleberger claims that the reason for the economic crisis of 1929 was that the United States did not want to become a balancing force due to the necessity of a hegemonic system power for world trade to function smoothly. The role of Great Britain in the world economy in the 18th and 19th centuries had to be undertaken by the United States in the 20th century, but in 1929 the world experienced a great economic crisis as they did not play the role. The United States had to undertake this role in the early 20th century, but after the Second World War, the Bretten Woods Decisions were made by the dollar being the currency of the world trade and thus starting to liberalize the world trade in a liberal war.

In the 18th and 19th centuries, the Great Britain and the United States in the 20th century need to be similar to the hegemonic role that the United States undertakes to achieve and enhance political and economic stability in the European Union. German Federal Finance Minister Wolfgang Schäuble said that the knowledge and experience of Kindleberger should be used in the 'Euro-Crisis'. Schäuble also underlined the fact that, in 2010, Kindleberger's message became more important than ever before. According to Schäuble, he referred to both states that Germany and France should accept the role of stabilizing hegemon in the European Union in the course 
of the post-World War II period, rather than in the years when the US did not see him as a stabilizing hegemon before the 1929 crisis. In the following period, he continued his leadership role by being passive in the Libyan crisis, but he was highly criticized for his passivity. On the other hand, the fact that it was actively involved in the Ukraine crisis and tried to give direction was criticized and not criticized by the US. he has taken an active role in the Syrian migrants' crisis. For the savvier approach towards immigrants than in other European countries, and because he chose the way of dealing with immigration agreement with Turkey was exposed to criticism from some leaders in Germany and some other countries.

As in the period of the Syrian migrant crisis, the non-compliance of member states with European Union regulations, institutions, and decisions taken by the heads of state and government has fueled the debate on the necessity of a strong hegemon within the Union. The unstable politics of the power of the Federal Republic of Germany damages the possibility of being hegemony. In addition, the need for joint action and cooperation within the Union is increasing when there is a full distribution of authority among the institutions of the European Union. The European Union is becoming more and more chaotic when it experiences the 'Euro-Crisis' immediately after the economic crisis, which has adversely affected the world, and immediately after it has lost United Kingdom with Brexit. And United Kingdom was one of the most important and powerful member of the European Union. Together with these important and major developments, the fact that there is no harmony and unity in the migratory crisis shows us that this chaotic environment which the Union has entered cannot easily get out. In this case, where the powers of the European Union institutions are limited, it would be much more optimistic to expect a Brussels-based solution to go there.

Another issue that needs to be taken into account is that the United States withdraws itself from Europe and moves towards the Far East. When we come to the present day, seeing the economic interests of the United States in Europe and not in Europe, and turning it more and more in a direction, has created the possibility of a political vacuum in Europe. Considering these developments in the international arena, we can say that a hegemonic power will be needed in the European Union. It is clear 
that this force cannot have Brussels because of the negative performance and the uncertainty in itself.

The political future of the European Union depends on the performance of Germany. The important thing for Germany is to learn from the mistakes of the past and not to repeat them. Thus, it can become a strong and decisive country of Continental Europe and the European Union. Germany can be accepted by the other countries of the Union as long as it leads the common interests of the Union and itself. One important point that German governments should take into consideration when acting in line with this expectation is to prevent the rise of anti-European opposition in their national public opinion. In order to prevent the rise of the opposition of the Union in public opinion, importance should be given to explain how important and necessary the European project is. Another important conclusion that we should mention is that the probability of Germany being able to direct or rule the Union in spite of the member states of the European Union is very low. Despite all the bitterness experienced by Germany in Europe, it is highly unlikely that other member countries will accept such a role.

\section{Kaynakça / References}

Aschauer, W. (2017). Das Gesellschaftliche Unbehagen in der EU, Springer Verlag, Wiesbaden.

Baumann, R. (2007). Deutschland als Europas Zentralmacht, Handbuch zur Deutschen Aussenpolitik, Verlag für Sozialwissenschaften, Wiesbaden.

Bredow, W. (2006). Die Aussenpolitik der Bundesrepublik Deutschland, Verlag für Sozialwissenschaften, Wiesbaden.

Geiger, W. (2017). Die Ermüdung der Demokratie, Humanities Online, Frankfurt.

Gollwitzer, H. (1972). Geschichte des Weltpolitischen Denkens, Vandenhoeck \& Ruprecht, Göttingen.

Jerabek, M. (2011). Deutschland und die Osterweiterung der Europäischen Union, Verlag für Sozialwissenschaften, Wiesbaden. 
Kleine, M. (2004). Die Reaktion der EU auf den 11. September, LIT Verlag, Münster.

Kiehen, H.- E. (2016). Angela Merkels Flüchtlingspolitik - Eine Bilanz des Versagens, BoD Books on Demand, Deutschland.

Menzel, U. (2015). Die Ordnung der Welt. İmperium und Hegemonie in der Hierarchie der Staatenwelt, Suhrkamp Verlag, Berlin.

Münkler, H. (2007). Imperien, Rowohlt, Hamburg.

Milosevic, N. (2012). Deutsche Kriegsbeteiligung und Verweigerung, Diplomica Verlag, Hamburg.

Reinhard Rode, R. (2002). Weltregieren durch Internationale Wirtschaftsorganisationen, LIT Verlag, Münster.

Sikorski, R. (2011). Deutsche Macht fürchte ich heute weniger als deutsche Untätigkeit, https://dgap.org/de/node/20029, (erişim 20.02.2018).

Sikorski, R. (2011). Ich fürchte die deutsche Untätigkeit. http://www.zeit.de/2011/49/P- Europa, (erişim 20.02.2018).

Sönmezoğlu, F. (2012). Uluslararası Politika ve Dış Politika Analizi, Der Yayınları, İstanbul.

T-Online (2015). http://www.t-online.de/nachrichten/ausland/krisen/id_72814542/us-kritik-an- merkels-ukraine-politik-ich-glaube-ihrmacht-einen-grossen- "fehler-.html, (erişim 28.02.2018)

Woyke, W. (1984). Europäische Gemeinschaft-Europäisches Parlament- Europawahl, Springer Verlag, Wiesbaden.

Zielenka, J. (2006). Europe as Empire, Oxford University Press, Oxford.

Zimmerman, H. \& Andreas Dür, A. (2016). Key Contrversies in EuropeanIntegration, Palgrave, London.

\section{Kaynakça Bilgisi / Citation Information}

Soytürk, M. (2019). Avrupa birliğinde hegemonya sorunu ve Almanya. OPUS-Uluslararası Toplum Araştırmaları Dergisi, 10(17), 2245-2262. DOI: 10.26466/opus.525395 